\title{
Modeling a Road Reinforced by Geosynthetics
}

\author{
Talhaoui Zakia, Fathi and Allal Mohamed Amine \\ Department of Civil Engineering, Faculty of Technology, \\ University of Abou Bekr Belkaid, B.P. 230 Chetouane, 13000 Tlemcen, Algeria
}

\begin{abstract}
Pavement construction is subject to the availability of good quality material, especially for the construction of the base and foundation layers. The use of geosynthetic reinforcement in these layers presents an interesting perspective on the shortfall. This research is in the context of the evaluation of the mechanical behaviour of flexible pavements reinforced by geosynthetics alveolar type of the AFITEX Company for which we started a modelling by the Software FLAC 2D Version 4 whose goal is to evaluate the deformations and the constraints. The pavement is subjected to a static loading of a value corresponding to 13 tons per axle.
\end{abstract}

Key words: Pavement, reinforcement, geosynthetics, displacement, FLAC 2D, material

\section{INTRODUCTION}

The roads are subject to the availability of good quality material, especially, regarding the construction of the base layer and foundation. So and whenever the shortage of good materials and the problems posed by their exploitation, transport and cost, the reinforcement solution will be indispensable. Geosynthetics have an interesting face these obstacles perspective, they are used in a variety of purposes such as: increasing service life and resistance to fatigue, minimize differential settlements and decrease total settlement, reduce ruts, so, it's building a sustainable structure. The purpose of this study is to evaluate, using numerical modelling on the SoftwareFLAC 2D V4(Finite Difference Calculation Code) the behaviour of the body of a flexible pavement in the elastoplastic domain with and without geosynthetic layers subjected at a static loading of 13 tons per axle (LCPC). The geosynthetic used in the study is three-dimensional honeycomb shape (Fig. 1).

Reinforcement of flexible pavements: On the Algerian road network near $110,000 \mathrm{~km}$ of roads, we find rather traditional structures (loose materials, tracks), flexible structures, some semi-rigid (treated with hydraulic binders dairy) and other rigid (airport pavements: concrete). For our research we limit ourselves to study the effect of reinforcement on the flexible pavements. They distribute the surface forces through the base and foundation layers. This distribution is done, so that, the effort on the platform is compatible with the strength of the infrastructure and the seat layer made of granular material. The reinforcement geosynthetics is

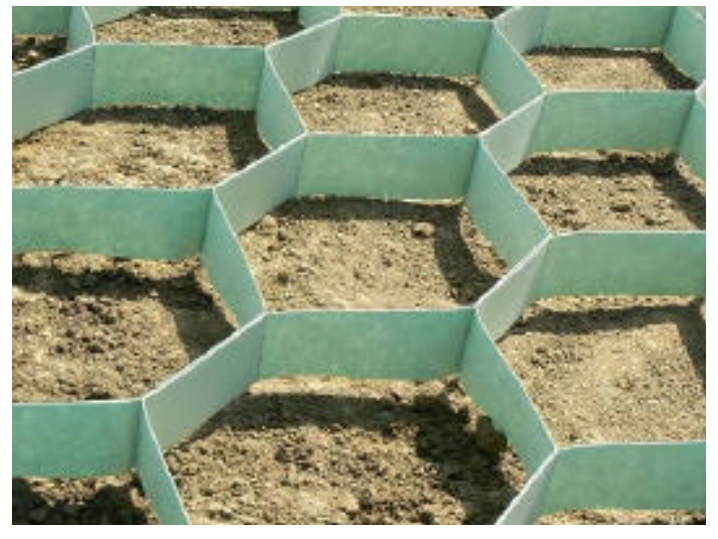

Fig. 1: Alveoter STD (AFITEX)

used to increase the characteristics of the soil as well as to prevent or reduce the compaction caused by insufficient bearing capacity of the foundation soil and by the lateral movement of the base material layer or the sub grade. Reinforcement also increases the service life of the roadway (Soude, 2011; Benmebarek et al., 2013).

In the study, we will research with a three-dimensional geotextile which is classified as a geo-container according to the French standards and the definitions of the International Geosynthetic Society, these cellular structures obtained by alternative connection (sewing or gluing) of rigid or semi-rigid bands-rigid. The cells are in the shape of hexagon or diamond. Typically these structures have been used until now for slope protection against erosion or for steep embankment construction.

Corresponding Author: Talhaoui Zakia, Department of Civil Engineering, Faculty of Technology, University of Abou Bekr Belkaid, B.P. 230 Chetouane, 13000 Tlemcen, Algeria 


\section{MATERIALS AND METHODS}

\section{Modelling and law of behaviour}

Law of soil behaviour: The FLAC 2D V4 Software makes it possible to define the different rheological laws in order to better model the behaviour of soils. All soil modelling are assumed to have elastoplastic behaviours and the Mohr-Coulomb failure criterion (Reiffsteck, 1996; Racana, 2002), the most commonly used model in soil mechanics that is characterized by five parameters, namely:

\section{In elasticity:}

- E modulus of elasticity of Young

- v Poisson's ratio

\section{In plasticity:}

- C Cohesion

- $\Phi$ angle of friction

- $\psi$ dilatancy angle

Modelling the interface between different layers: In the pavement structure by interface between road layers, the contact zone between two layers of materials is defined.

Depending on the nature of the materials used and the arrangements made, two scenarios exist to model the interface between layers of a roadway: either bonding (it ensures the continuity of normal and tangential movements in all points of the interface), either possibility of sliding of one layer by contribution to the other (the normal displacements must be equal on both sides of the interface and the shear stresses null to the right of this one). In the FLAC 2D Software, the properties of the interface are available in 3 levels: glued, unbounded and bonded, each with progressively more properties.

In the end, the hypothesis adopted for the type of interface is adhesion (Glued) with an isotropic linear elastic behaviour (Diakhate 2007, Le Hello, 2007). The (glued) interface is represented as the inter-particle stiffness, normal $\mathrm{Kn}$ and shear $\mathrm{Ks}$ between two planes that can come into contact with one another (Racana, 2002).

Law of behaviour of geosynthetics and their interface: In order to simulate the alveolar reinforcement plies, structural elements are implemented. The type of element that can be used to model the reinforcement plies: the cable elements.

This reinforcing element (Fig. 3) has membrane behaviour. The formulation of the cable element considers the effect of the reinforcement: the resistance to deformation is taken into account along the total length.

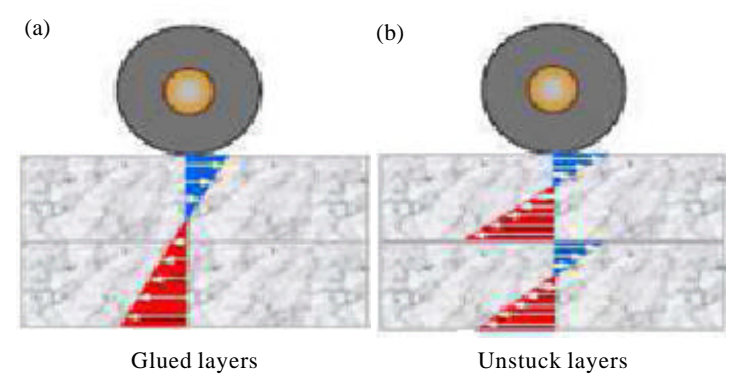

Fig. 2: The two types of interfaces in a roadway

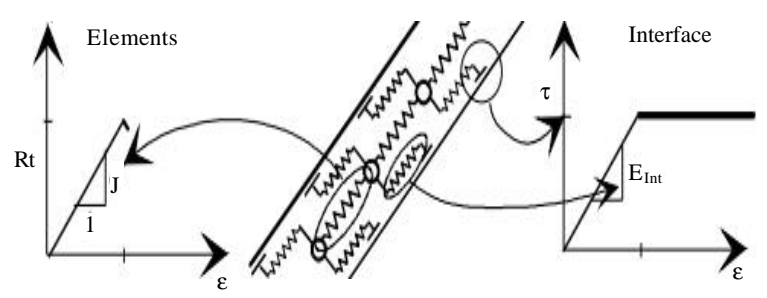

Fig. 3: Model applied to the cable element and its Interface (ITA-02)

Presentation of the problem: The pavement is subjected to a static loading equal to 13 ton per axle (CTTP 2001, B40). It is governed by the law of Mohr-Coulomb elastic perfectly plastic. The proposed cross-section of the roadway will consist of a $12.50 \mathrm{~m}$ platform supporting a bidirectional $6 \mathrm{~m}$ pavement with a $1.0 \mathrm{~m}$ shoulder on both sides. The proposed geometries are presented in Fig. 4 and 5 .

The modelling of the pavement is carried out in two stages, one without reinforcement and another one introducing the geosynthetic.

The study was conducted considering the mechanical characteristics of the different materials constituting the model (soils, geosynthetics) (Table 1). The mechanical parameters characterizing the behaviour of soils and asphalt are derived from indicative values for a so-called "all-out" soil category 1 for the base layer, "all-comers 2 " for the base layer and bituminous concrete for the wearing course. The two all-comers used in the modelling have less weighty characteristics by contribution to a noble material such as the crushed bass and the serious bitumen.

The characteristics at the soil-soil interface were determined by considering good gluing characteristics. The inter-particulate stiffness values $\mathrm{Kn}$ and $\mathrm{Ks}$ of the soil were determined from the results of tensile tests carried out in the laboratory. The values taken into account in this study are as follows: 
Table 1: Characteristic of materials (CTTP)

\begin{tabular}{lcccccc}
\hline Variables & Thickness $(\mathrm{cm})$ & Young's modulus $(\mathrm{MPa})$ & Volume mass $\left(\mathrm{kg} / \mathrm{m}^{3}\right)$ & Cohesion $(\mathrm{kPa})$ & Friction angle $\left(^{\circ}\right)$ & Poisson coefficient \\
\hline Foundation layer & 55 & 20 & 1800 & 10 & 30 & 0.35 \\
Base layer & 30 & 120 & 2000 & 5 & 30 & 0.35 \\
Layer of bituminous mix & 20 & 5400 & 2200 & 50 & 28 & 0.35
\end{tabular}

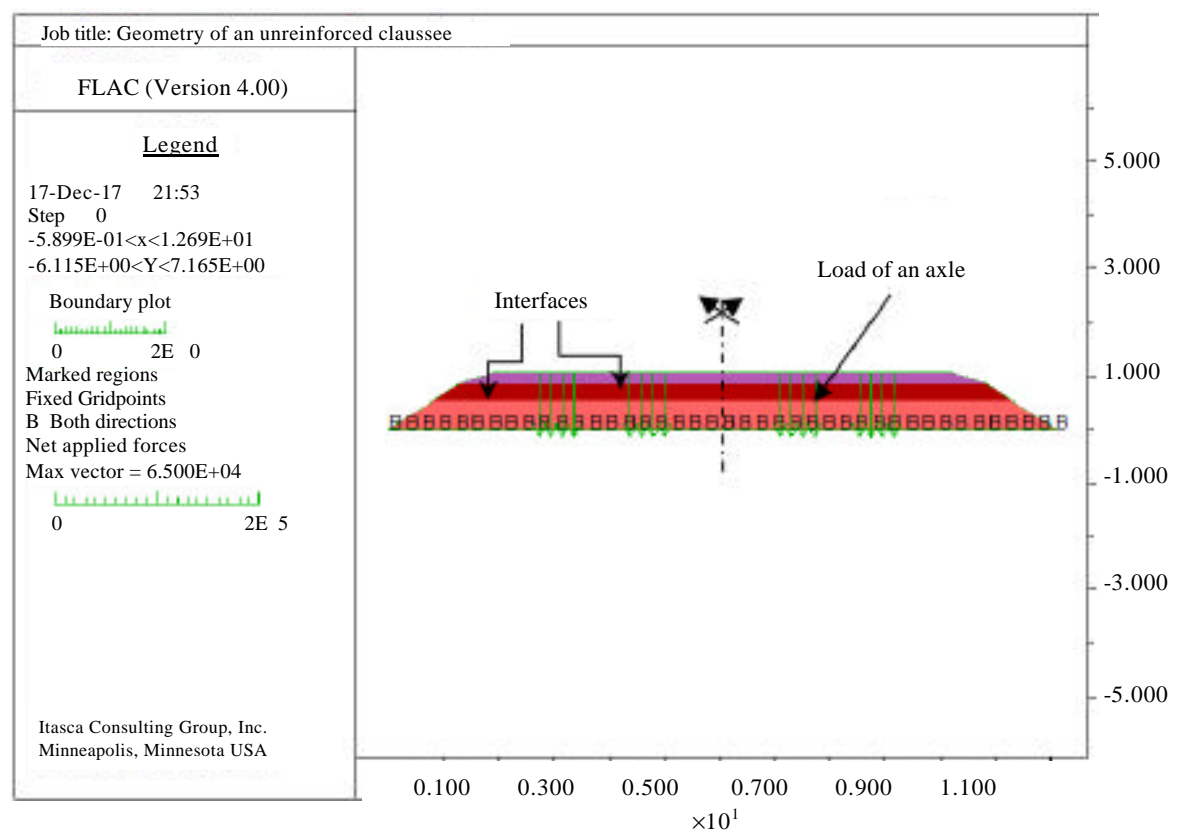

Fig. 4: The geometry of an unreinforced pavement fixed at the base and undergoing loading of a 13-ton axle (FLAC2D)

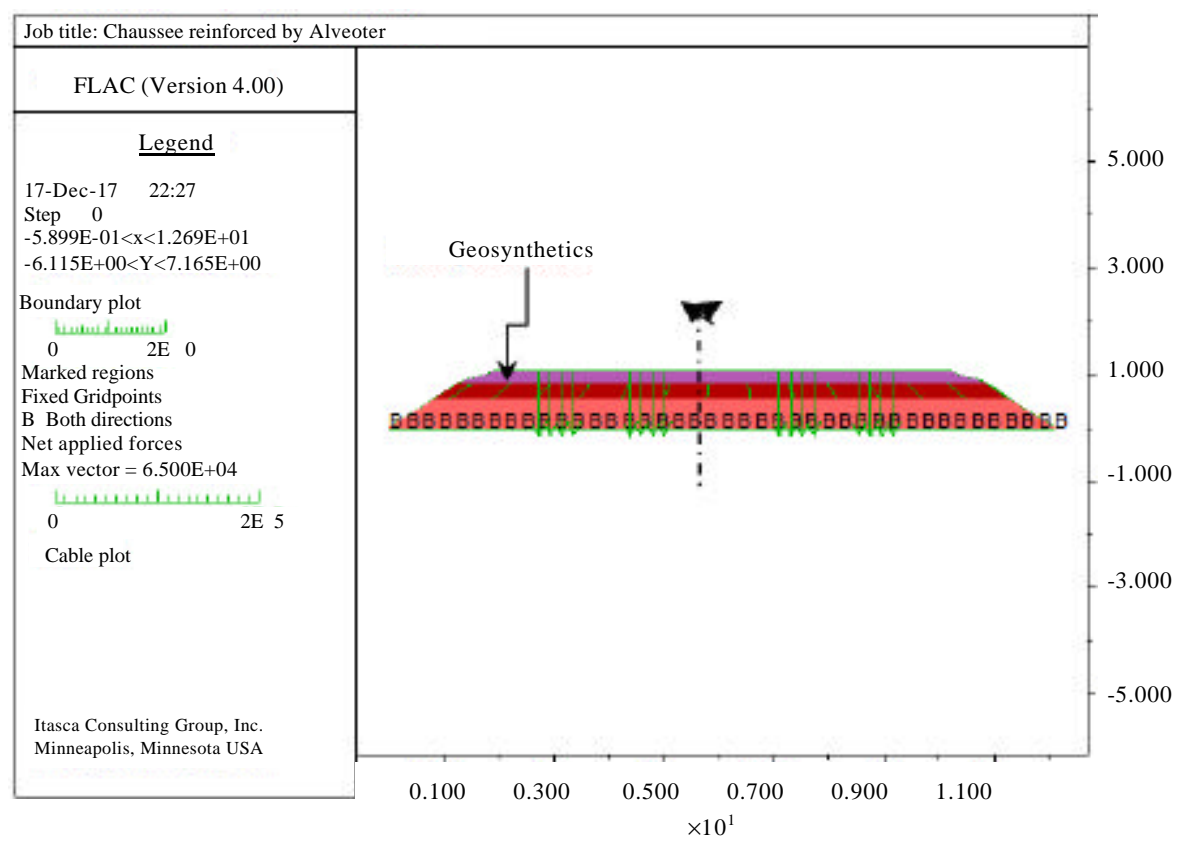

Fig. 5: The geometry of a road reinforced by Alveoter in the base layer

- $\mathrm{Kn}=\mathrm{Ks}=7.6 \times 10^{8} \mathrm{~Pa} / \mathrm{m}$ for interface 1 (between foundation layer and base layer)
- $\mathrm{Kn}=\mathrm{Ks}=9.08 \times 10^{9} \mathrm{~Pa} / \mathrm{m}$ for interface 2 (between basecoat and asphalt layer) 


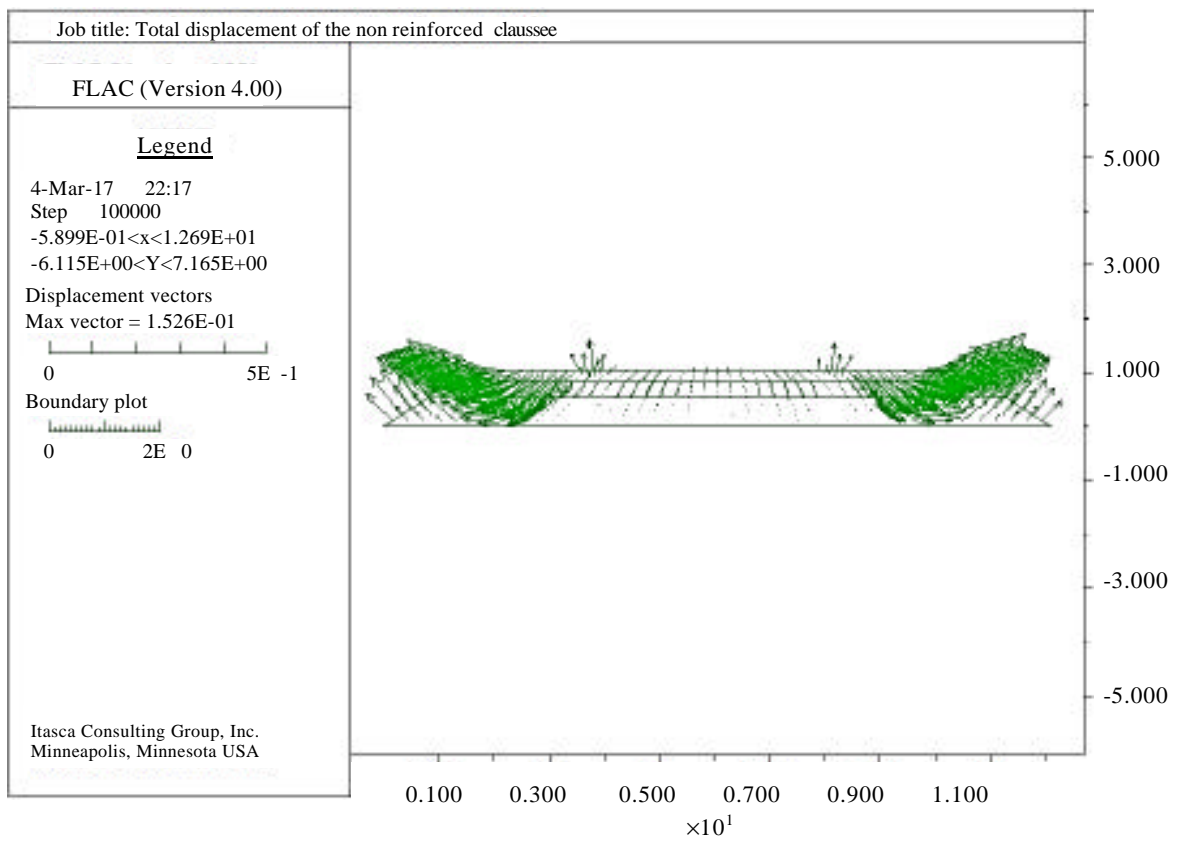

Fig. 6: Total deformation of the pavement without geosyntetic (FLAC 2D)

Table 2: Geosynthetic feature (AFITEX)

\begin{tabular}{lllc}
\hline Characteristics & Physicals & - & NF EN 9864 \\
Height of the cells & $0.20 \mathrm{~m}$ & Panel mass surface & NF EN ISO 10319 \\
Small side of the cells & $0.10 \mathrm{~m}$ & Tensile strength & NF EN ISO 10319 \\
Large side of the cells & $0.125 \mathrm{~m}$ & Shear strength of bonds & 15 kN/m \\
Thickness of the bands & $2.2 \mathrm{~mm}$ & Peel strength of the bonds & NF EN ISO 10319 \\
\hline
\end{tabular}

AFITEX's ALVEOTER ${ }^{\circledR}$ non-woven geotextile is applied to the base layer at a height of $75 \mathrm{~cm}$ from the support floor and represents characteristics according to Table 2 .

Numerical studies: After initialization of the geometry and boundary condition and once the computation is complete, the results are obtained which carry the data of the maximum and vertical total displacement and the mechanical resistance resulting from external forces applied. This choice of these maximum values turns out to be rather representative indicators of the state of reinforcement.

Deformation: The foundation layer contains a less rigid material and is under the base layer which has a stiffness modulus improved by that of the geosynthetics then and as a result the deformation on the surface will be lower and more uniform.

As a result, the use of geosynthetics in the base layer would allow a reduction in total displacement of $15.26 \mathrm{~cm}$ before reinforcement and $6.53 \mathrm{~cm}$ after reinforcement, a
Table 3: Results of displacements of reinforced and unreinforced

\begin{tabular}{lcc}
\hline & Displacement FLAC 2D & \\
Variables & Total (cm) & Vertical (cm) \\
\hline Without geosynthetics & 15.26 & 10.00 \\
With geosynthetics & 6.53 & 4.00 \\
reduction (\%) & $57 \%$ & $60 \%$ \\
\hline
\end{tabular}

reduction of $57 \%$. On the other hand, a vertical reduction which is of the order of $10 \mathrm{~cm}$ before reinforcement and $4.00 \mathrm{~cm}$ after reinforcement, a reduction of $60 \%$ (Fig. 6-9 and Table 3).

The results of the elastoplastic analysis indicate that the presence of the geosynthetic reduces the vertical displacements following the application of the load compared to the unreinforced case.

Also, the results show that there is a proportionally inverse variation of the rigidity with the displacement which is logical, since, the stiffness of alveoter is greater than that of the ground, so, it is about the stiffness of the geosynthetic which goes minimize soil displacement and deformation of the structure. 


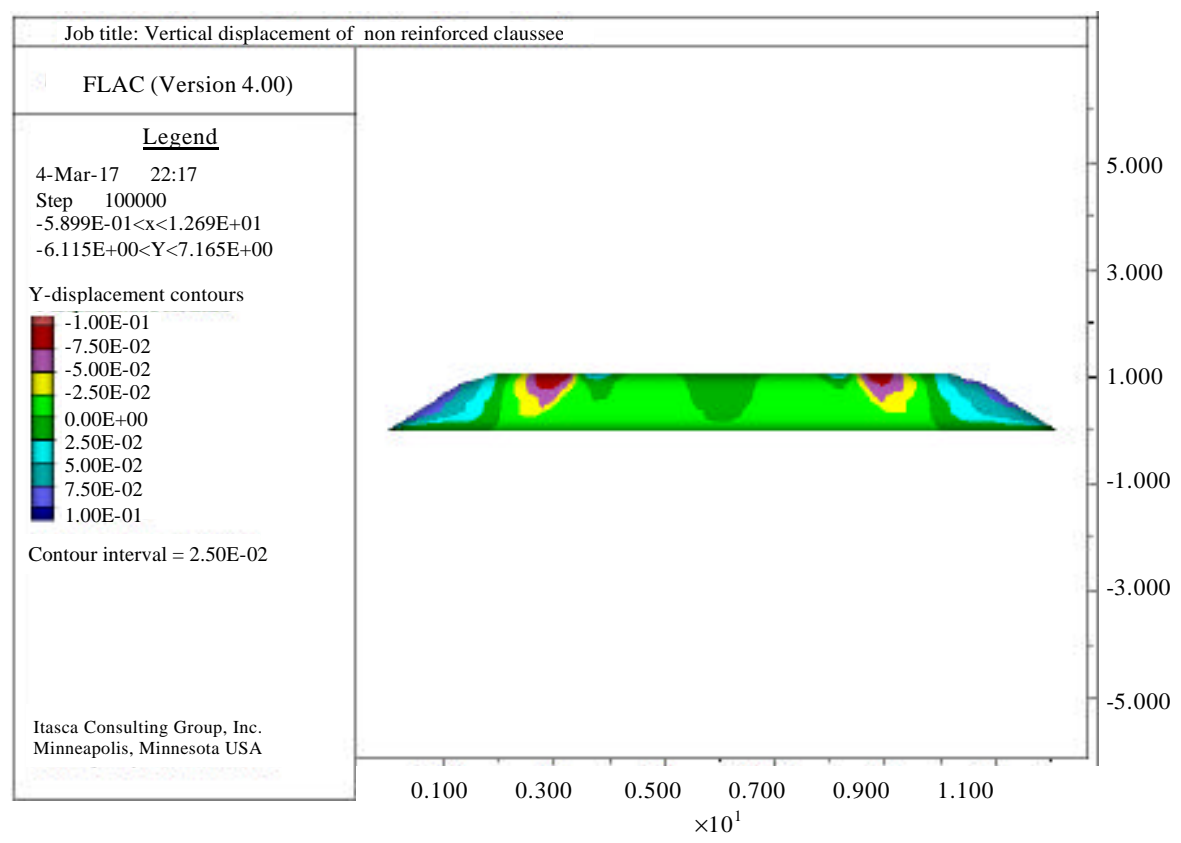

Fig. 7: Vertical displacement of an unreinforced pavement (FLAC 2D V4)

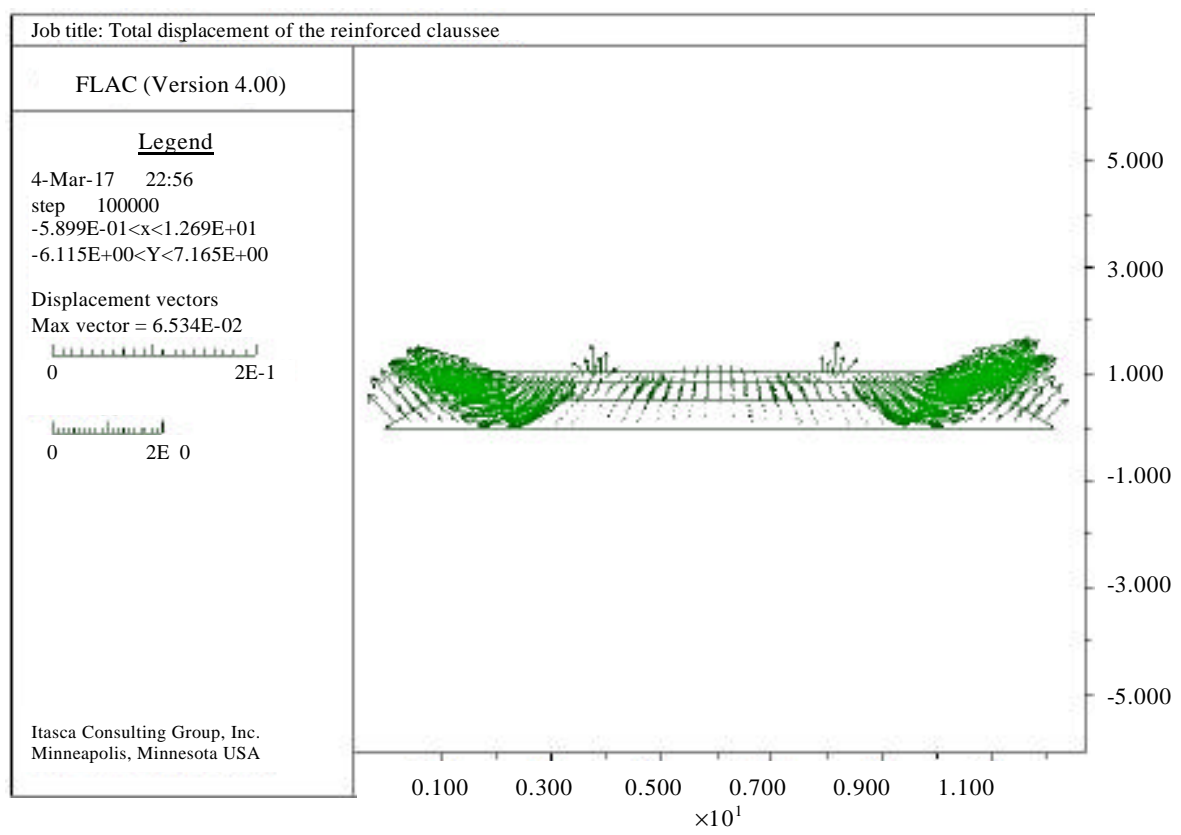

Fig. 8: Total deformation of the pavement with geosyntetic (FLAC 2D)

Stresses: The presence of a layer of geosynthetic in the base layer can lead to an increase in rigidity which leads to an improved and more widely distributed vertical stress.

The reduction of the vertical stress $(\Delta \sigma Z)$ is $5 \%$ in the control case and $10 \%$ in the reinforcement case. The geotextile sheet has thus played its role of force distribution: the vertical load is spread over a larger area, resulting in a reduction in the stress transmitted vertically (Fig. 10 and 11).

The distribution of normal stresses and the reduction of shear stresses: For most types of structures used in the road domain, their success is essentially linked to the 


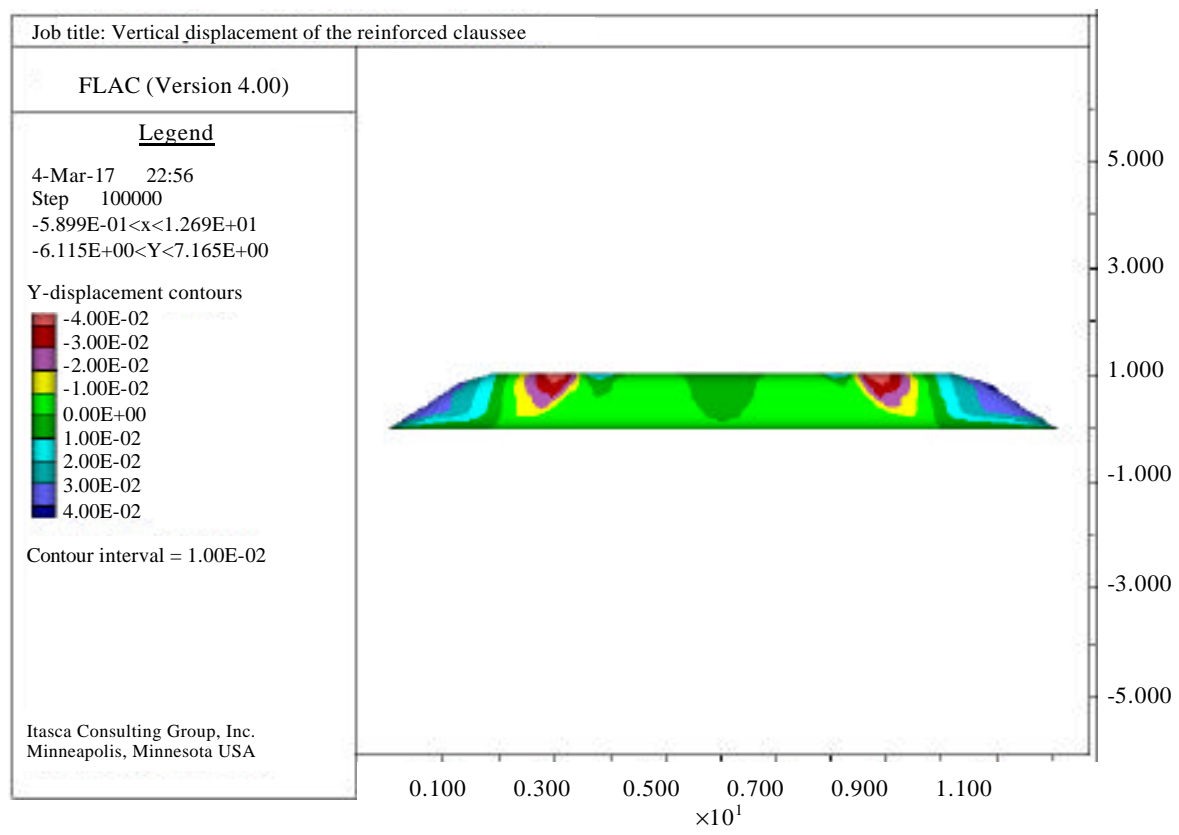

Fig. 9: Vertical deformation of the pavement with geosyntetic (FLAC 2D)

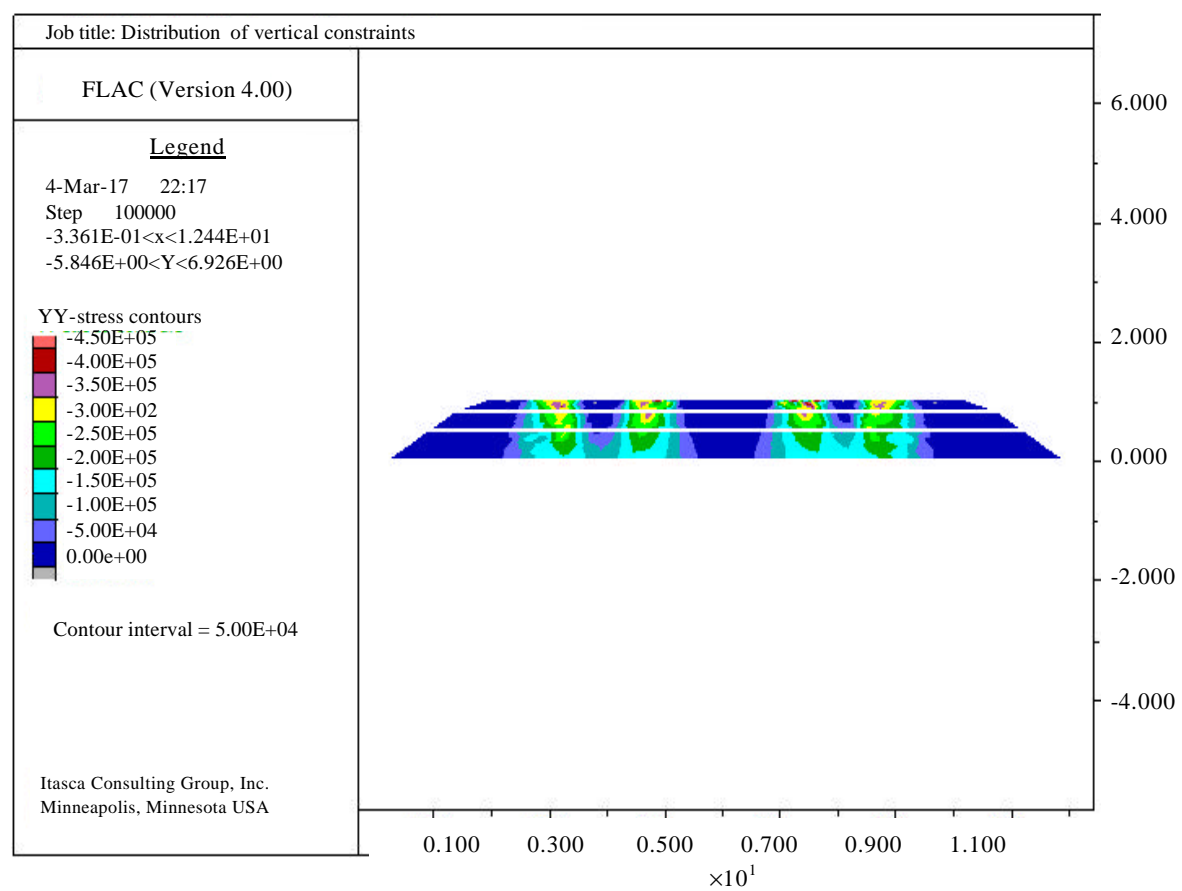

Fig. 10: Vertical stress distribution of an unreinforced pavement

assumption that good bonding is assured at the interface of certain layers of materials. As long as the different layers of material remain stuck together, the pavement structure behaves like a monolithic block. In our case, the role of geosynthetic reinforcement allows the overall rigidity to increase.
One of the beneficial effects of geosynthetic reinforcement at the interface is precisely to withstand the shear stresses induced by vehicle loads at the interface, it is expected that the shear deformation transmitted from the upper layer to the lower layer decreases. 


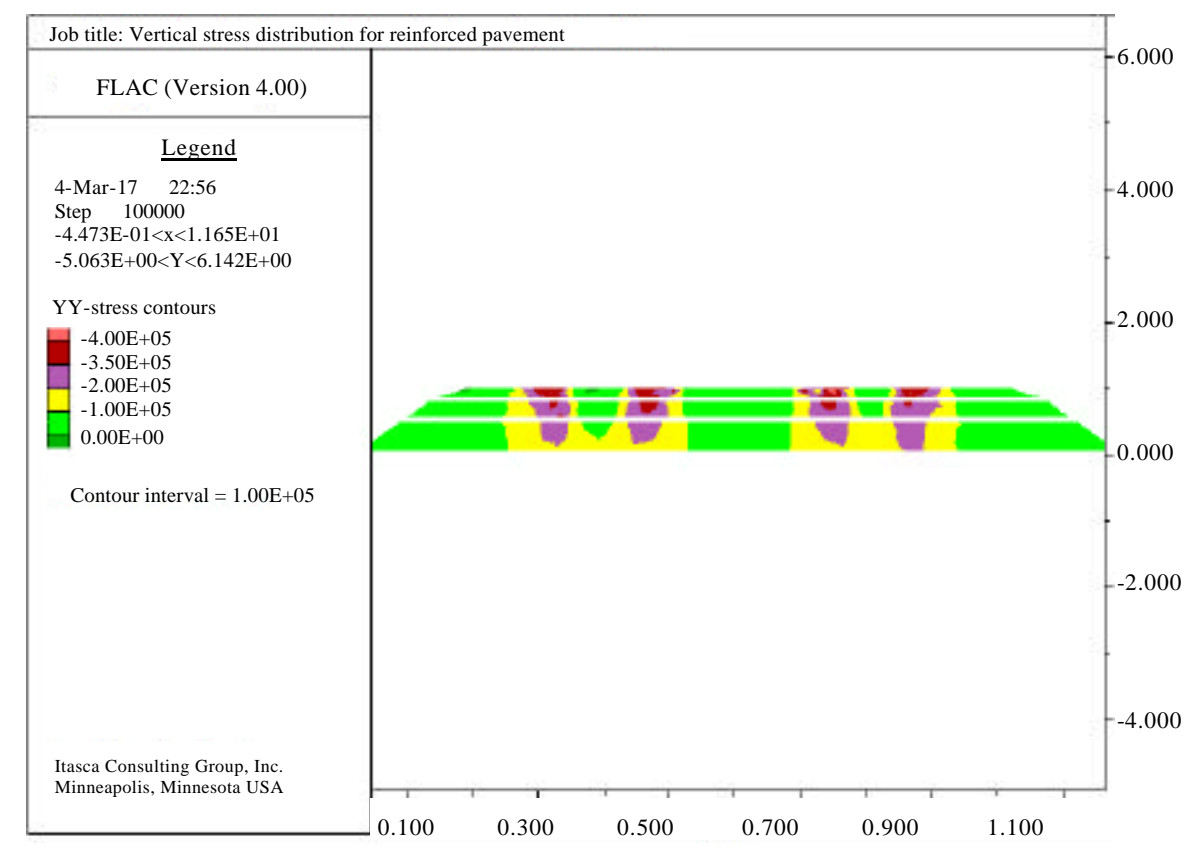

Fig. 11: Vertical stress distribution of a reinforced pavement

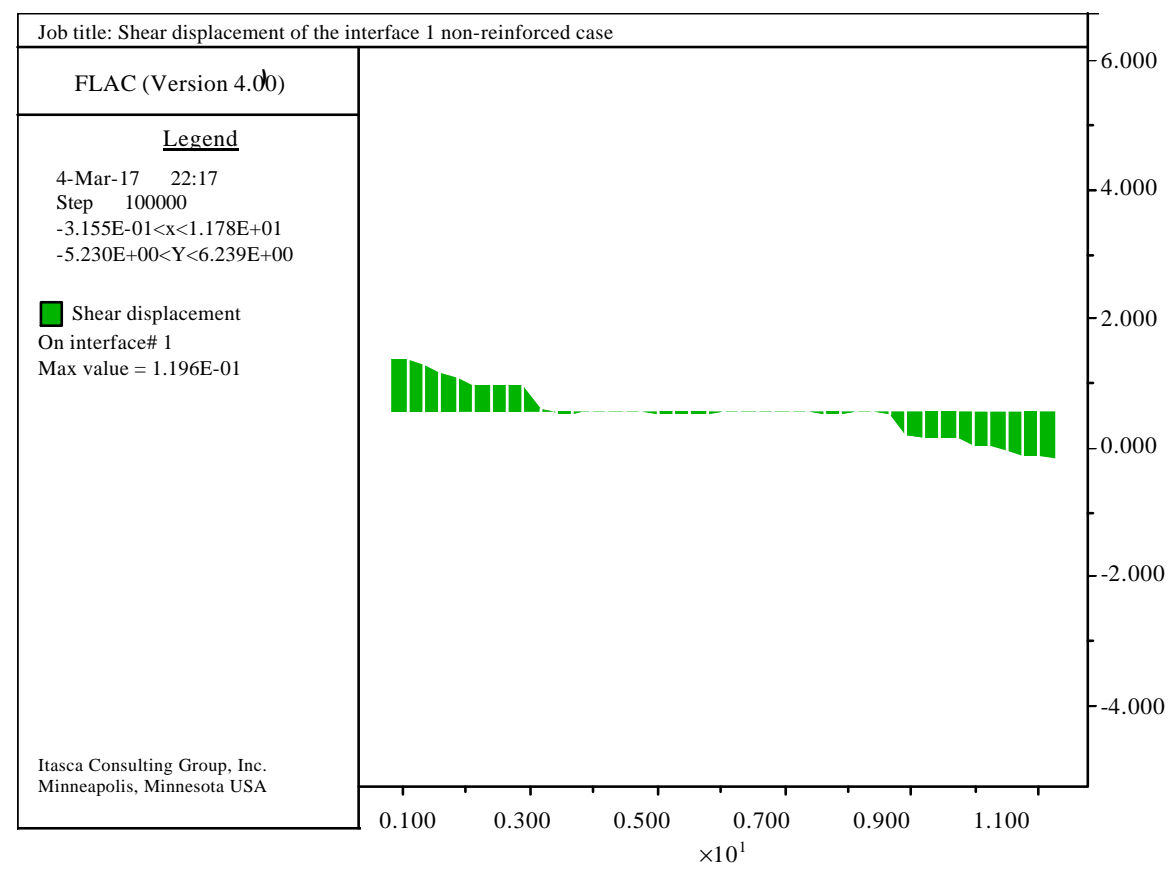

Fig. 12: Shear displacement of interface 1 of an unreinforced pavement

Yet, it is known that shear stresses transmitted from the top layer to the bottom layer may be oriented outward or inward. Generally, the shear stresses induced by the loads of the vehicles tend to be oriented outwards which decreases the carrying capacity of the ground. However, in the presence of geosynthetics, soil shear will transmit tension forces to reinforcement (Fig. 12-15). 


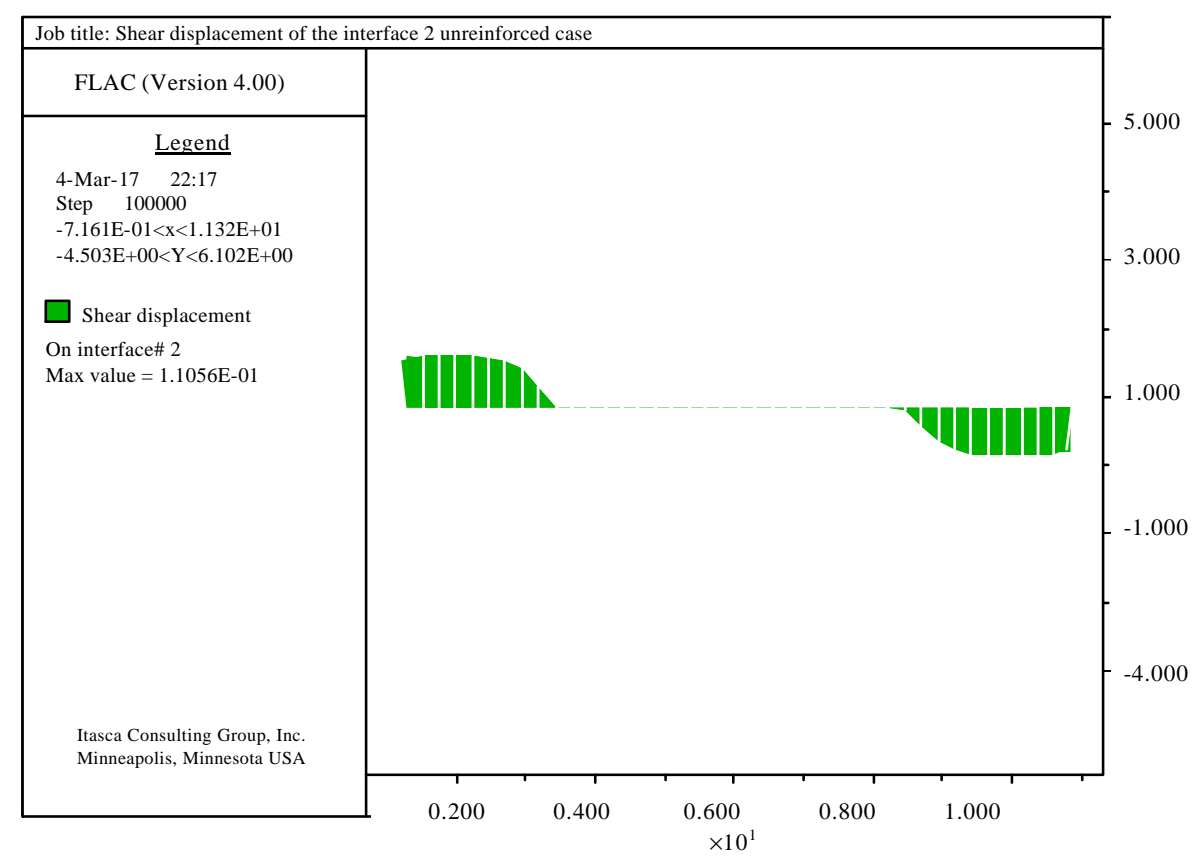

Fig. 13: Shear displacement of the interface 2 of an unreinforced pavement

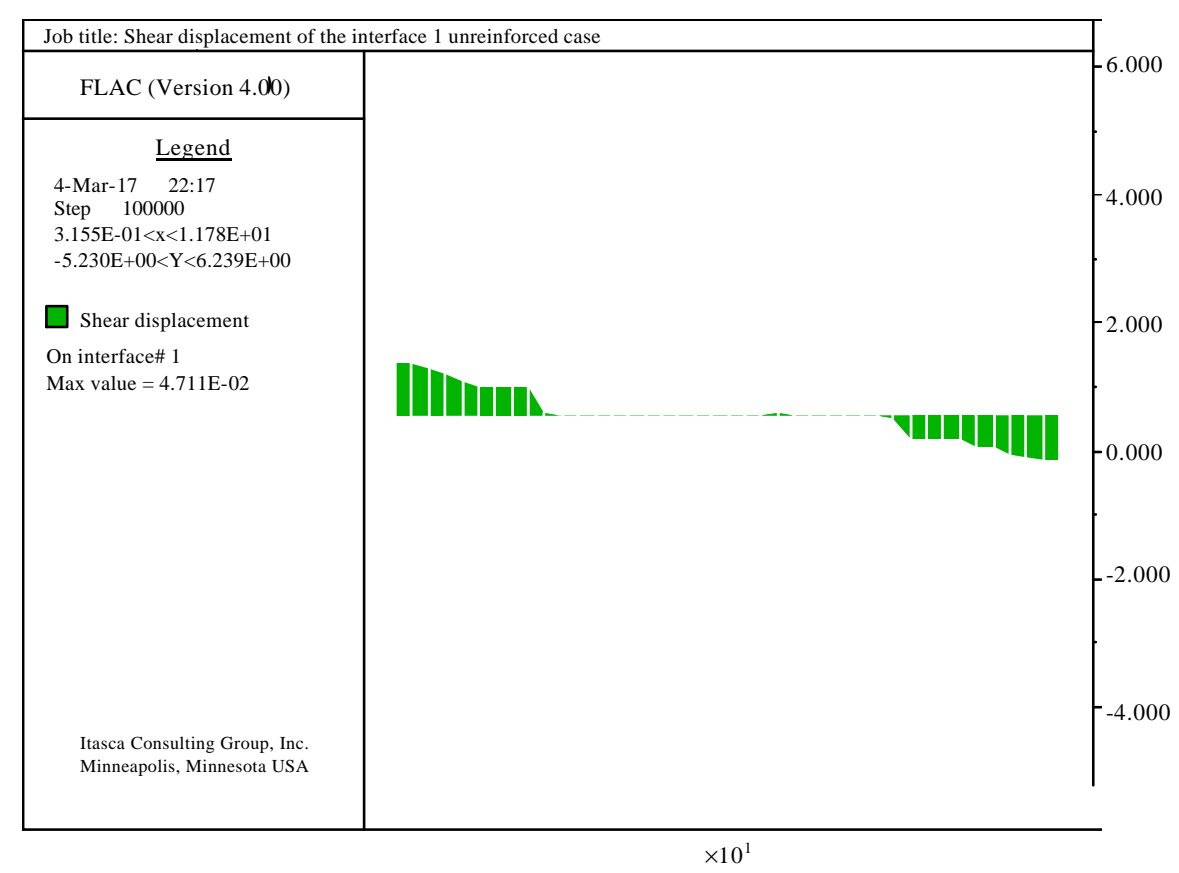

Fig. 14: Shear displacement of the interface 1 of a reinforced pavement

According to the Fig. 12-15 and Table 4, one can have the shear deformations in the interfaces 1 and 2 are decreased of $11.96 \mathrm{~cm}$ before reinforcement to $4.71 \mathrm{~cm}$ after reinforcement (interface 1) and of $10.56 \mathrm{~cm}$ before reinforcement to $4.21 \mathrm{~cm}$ after reinforcement (interface 2), $\underline{\text { Table 4: Normal displacement of interfaces }}$

Normal displacement $(\mathrm{cm})$

Variables Interface 1 Interface 2

Not reinforced $\quad 9.47 \quad 12.30$

$\underline{\text { Reinforced }}$ 


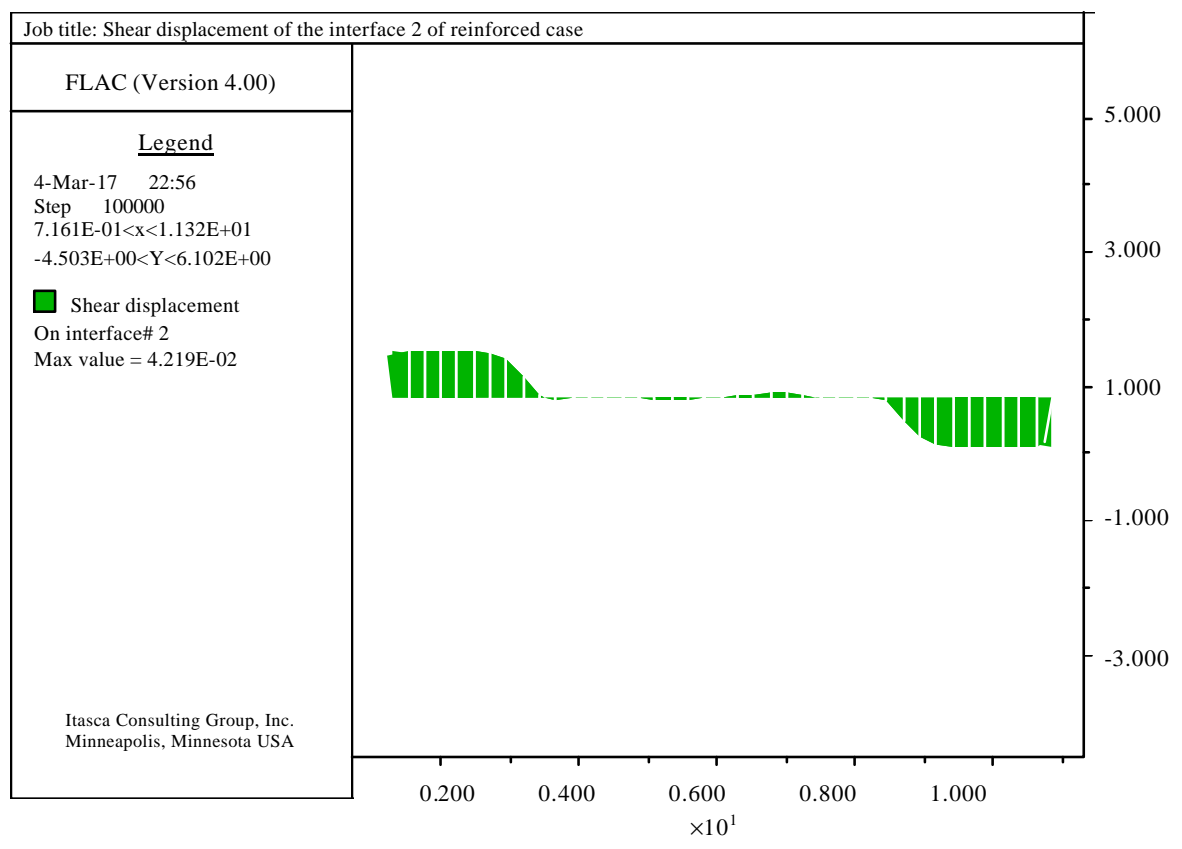

Fig. 15: Shear displacement of the interface 2 of a reinforced pavement

\section{CONCLUSION}

View results made from FLAC V4 Software interesting conclusions seem to appear. We carried out the modelling of the roadway in two stages, one without reinforcement and another by introducing the geosynthetic in the base layer. This choice of the layer is done in order not to do again what happens in practice, i.e. in the upper part of earthworks or part of bituminous mix.

On the other hand, the calculations made it possible to draw the following conclusion: The results of the elastoplastic analysis indicate that the presence of the geosynthetic reduces the vertical displacements following the application of the load compared to the unreinforced case. A reduction in the intensity of the shear stresses transmitted to the foundation soil. The results show that there is a proportionally inverse variation of rigidity with displacement which is logical because it is the stiffness of the geosynthetic which will minimize the displacement of the soil and the deformation of the structure. So, under a static load, the bearing capacity increases with increase of this rigidity because it contributes to improve it.

\section{REFERENCES}

Benmebarek, S., M.S. Remadna and L. Belounar, 2013. Numerical modeling of reinforced unpaved roads by geogrid. Online J. Sci. Technol., 3: 109-116.

Diakhate, M., 2007. [Fatigue and behavior of tie layers in pavement structures]. Ph.D Thesis, University of Limoges, Limoges, France. (In French)

Le Hello, B., 2007. [Geosynthetic reinforcement of embankments on rigid inclusions, full-scale experimental study and numerical analysis]. Ph.D Thesis, University of Grenoble, Grenoble, France. (In French)

Racana, N., 2002. [Study of the mechanical behavior of a solid soil reinforced with cellular geotextile]. Ph.D Thesis, Blaise Pascal University, Clermont-Ferrand, France. (In French)

Reiffsteck, P., 1996. [Study of the mechanical behavior of the three-dimensional alveolar geotextile Armater]. Ph.D Thesis, Blaise Pascal University, ClermontFerrand, France. (In French)

Soude, M., 2011. [Study of the dynamic behavior of a massif in soil reinforced with M3S® cellular geotextile]. Master Thesis, Blaise Pascal University, Clermont-Ferrand, France. (In French) 